\title{
DESIGN AND SIMULATION OF AN AXIAL FLUX PERMANENT MAGNET GENERATOR FOR LOW POWER AND LOW SPEED USING FINITE ELEMENTS
}

\section{S. T. PIRACOCA PERALTA ${ }^{1}$, E. RIVAS TRUJILLO ${ }^{2} \&$ H. MONTANA QUINTERO}

${ }^{1}$ Engineering School, Engineering Electrical Student at Universidad Distrital Francisco Jose de Caldas, Bogota, Colombia

${ }^{2}$ Engineering School, Tenured Professor at Universidad Distrital Francisco Jose de Caldas, Bogota, Colombia

${ }^{3}$ Engineering School, Engineering Doctorate student in Universidad Distrital Francisco Jose de Caldas, Bogota, Colombia

\section{ABSTRACT}

Axial fluxgenerators are machines used in wind power generation systems, therefore, this document presents an analysis of an axial flux permanent magnet generator for low speed and low power. The proposed topologyis a purely coreless double rotor generator, with trapezoidal winding, with a Halbach matrix for permanent Neodymium magnets in order to eliminate iron in the rotor discs, and has 12 magnetic poles. The topology design and arrangement of the windings and magnets around the circumference of the disks is described. 2D finite element analysis in COMSOL software is used to simulate the proposed topology, the results obtained show that the purely coreless topology has good performance and can beused for low power and low speed applications.

KEYWORDS: Axial Generator, Double Rotor, Low Power, Low Speed, Finite Elements

Received: Jun 09, 2020; Accepted: Jun 29, 2020; Published: Sep 28, 2020; Paper Id.: IJMPERDJUN20201453

\section{INTRODUCTION}

Currently, the increase in energy needs requires finding new solutions sothat permanent magnet generators can easily supply energy with small-scale wind turbines without suffering voltage accumulation and without running the risk of excitation losses, thatis, a generator of permanent magnets is a machine that can convert the kinetic energy of the windint oelectrical energy [1].

The axial flux permanent magnet generator (AFPMG) is a machine made up of rotor and stator discs mounted on the same axis that passes throughits center [2], in which the excitation is replaced by permanent magnets located on the disc rotor with axial magnetization, for which the term axial flux arises, since when the rotor rotates it produces a magnetic field parallel to the axis of rotation and induces a voltage in the stator windings [3-5].

This type of generators have several advantages compared to other maquilas, such as a more compact structure, due to a shorter axial length, higher power / weight ratio and torque density, a more flexible magneticfield produced by permanent magnets and better cooling, which makes them more suitable for low-speed wind turbines [6], and various industrial applications, such as the propulsion of ships, and electric vehicles [7].

The increasing research on the design and construction of AFPMG has attracted increasing scientific interest in recentyears, however, there are very few studies on low speed and low power generators, therefore, this document aims to design and simulate a fully core less axial flux permanent magnet generator for low speed and low power, for this, itis advisable to use finit eelement programs to refine the design of the machine, avoiding problems of rebuilding the machine. 


\section{TOPOLOGIES OF AXIAL FLUX PERMANENT MAGNET GENERATOR}

The AFPMG are characterized by the arrangement and quantity of discs, since it allows variations, this means that they have several possibilities of structure in relation to the stator and rotor discs, which results in different topologies [3,8-11]:

- $\quad$ Single sided

- Doublesided: Two rotors and a single stator

TORUS

Rotors variants.

Two stators and a single rotor (AFIR).

- Multidisc

On the other hand, the AFPMG can also beclassified according to the type of stator, therefore, the stator can bebuilt with ferromagnetic material (core type), and this can beslotted or slotless, or with non-magnetic materials (coreless) [7,8,1114].

\subsection{Single Sided Generator}

The single-sided generator, shown in figure 1a, includes two discs, one is the stator disc and the other is the rotor disc, in which the windings and permanent magnets are placed respectively. The arrangement of the magnets in this topologyis North-South-North-South (NSNS) around the circumference of the rotor [3,8,12], as seen in figure $1 \mathrm{~b}$.
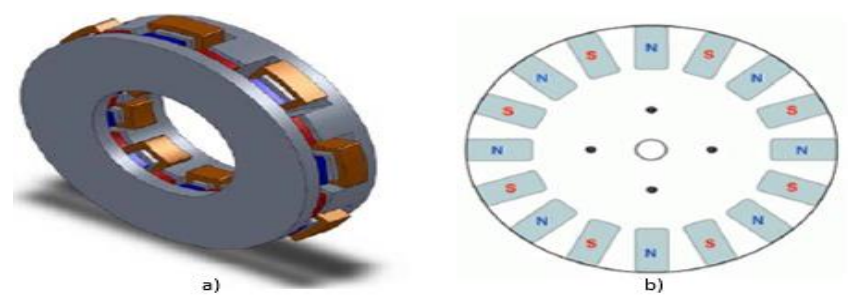

Figure 1: Single-Sided Generator: a) Topology [3], b) Magnet Arrangement [8].

This configuration is the simplest of all [12], however, it presents a great force of attraction between the magnets of the rotor and stator, causing the displacement of some of the discs, therefore, to prevent this displacement without the need for implement a magnetic bearing, two variants are generated by adding an additional stator or rotor disc, so that the force is balanced [3,10], which are described in figure 2 .

Variant with Stator Balance

Another stator disc is added, to prevent the rotor from moving in the direction parallel to the axis of rotation, and thus introduce an effective way to balance the force of attraction between the discs, for which, it is necessary to put permanent magnets in the opposite side of the rotor, to produce the necessary magnetic field and induce the balancing force [10].

\section{Variant with Rotor Balance}

An additional magnet rotor is added to the construction, whereby, the length of the stator must be extended to provide a path for the magnetic field through which the balancing force will be induced. Due to its design characteristics, this construction uses more materials than the variant with stator balanced [10].

Figure 2: Variants with Disc Balance.

\subsection{Double Side Generator}

The double-sides generator is also called two-side generator, sinceitis composed of three discs, of which two can berotor 
discs and one stator disc (double rotor), or they can be two stator discs and a rotor disc (double stator), as seen in figure 3. This topologydoes not present great concern due to the mechanical forces between rotor and stator, sincethey cancel out during operation, due to the double air gap it makes the total force affecting the internal disksmall $[8,15,16]$.
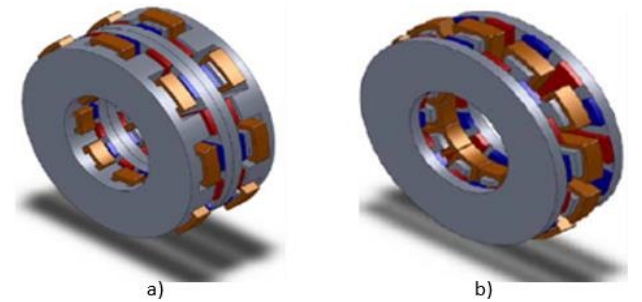

Figure 3: Two-Sided Generator: a) Double Stator b) Double Rotor [3].

\subsubsection{Two Rotors and Single Stator.}

In this configuration the permanent magnets can be arranged in a NSNS way as mentioned above [8, 12, 13], or in such a way that all the $\mathrm{N}$-pole magnets are on one rotor disc and the S-pole magnets on the other disc. [8], as shown in figure 4:
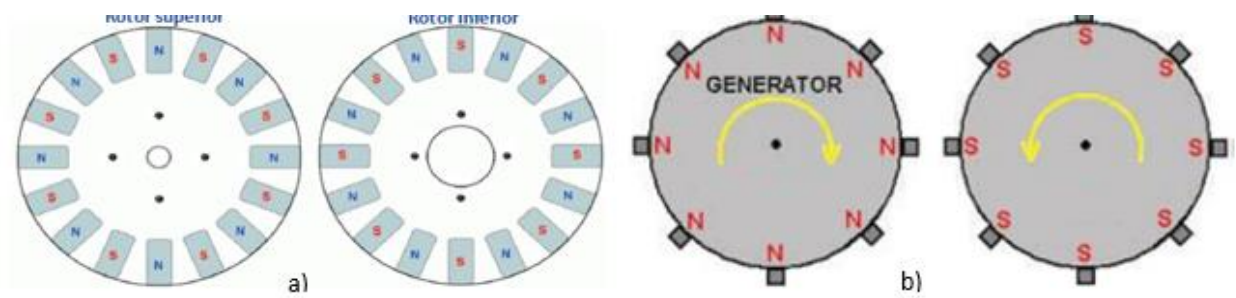

Figure 4: Rotor Discs with Permanent Magnets: a) NSNS Arrangement, b) N Poles on one Rotor and S Poles on the other [8].

The unique characteristic for this arrangement ( $\mathrm{N}$ Pole of one rotor faces the $\mathrm{S}$ Pole of the other rotor), allows the magnetic flux to passfrom one rotor to another crossing the stator thus completing the magnetic circuit, which allows the stator disc have a non-conductive or non-magnetic material, which makes it lighter [2].

It is important to note thatthisis the most widely accepted topology in low-speed power applications since, due to its configuration, a greater flow is achieved in the air gap, italsorequires the lowest mass of permanent magnets, a lowstarting torque and a low weight $[9,17]$. Some variations of the double rotor topology are presented in the literature:

\subsubsection{Toroidal Stator Generator or TORUS}

The name TORUS was adopted to indicate the toroidal nature of both the core and the stator winding [18], which can beseen in figure 5.

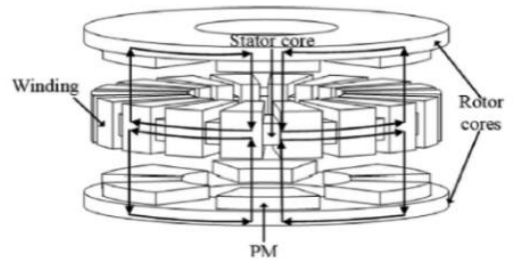

Figure 5: Generator with Toroidal Stator [19].

The main characteristics of this topology are $[10,18]$ :

- The rotor discs and magnets naturallyact as fans, ensuring good ventilation and cooling of the stator winding, even 
at lowrotational speed.

- Greater air space, makingthis configuration the mostsuitable for low power wind turbine applications.

\subsubsection{Built-in Radio Type Variants (See Table 1).}

This variation arises from replacing the rotor iron with permanent magnets in the form of parallel bars and interleaved pieces of iron, which are the magnetic poles of the rotor. This built-in radio type arrangement allows a higher flux density in the magnetic poles, offers the following benefits and reduces the air gap due to the integration of the magnets in the rotor [6, 20]:

Table 1: Built-in Radio Type Double Rotor Variants

\begin{tabular}{|c|c|c|}
\hline $\begin{array}{l}\text { A rotor disc structure with built-in } \\
\text { radius-type ferrite permanent } \\
\text { magnets and interleaved iron pieces }\end{array}$ & $\begin{array}{l}\text { The ferrite magnets and interleaved iron bars are the } \\
\text { magnetic poles of the rotor [6]. The only structural } \\
\text { change of the rotor resides in the partial cutting of }\end{array}$ & $\begin{array}{l}\text { In this structure, each } \\
\text { magnetic pole of the rotor } \\
\text { consists of five parts (see } \\
\text { figure } 6 \mathrm{c} \text { ): } \\
\text { Two ferrite magnet bars }\end{array}$ \\
\hline $\begin{array}{l}\text { is presented, which constitute the } \\
\text { magnetic poles of the rotor, thus } \\
\text { avoiding the rear iron of the same } \\
\text { (figure 6a) [6]. }\end{array}$ & $\begin{array}{l}\text { the ferromagnetic core of each rotor pole with the } \\
\text { dual purpose of increasing the flux density of the air } \\
\text { space and reducing the total weight of the generator } \\
\text { (figure } 6 \mathrm{~b} \text { ) }[6,20] \text {. }\end{array}$ & $\begin{array}{l}\text { Two pieces of iron } \\
\text { intercalated, separated by a } \\
\text { central bar of magnet } \\
\text { (Neodymium, Iron and } \\
\text { Boron) with axial } \\
\text { magnetization [6]. }\end{array}$ \\
\hline
\end{tabular}

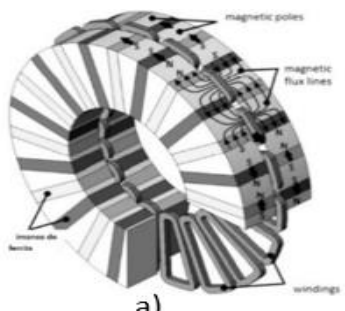

a)

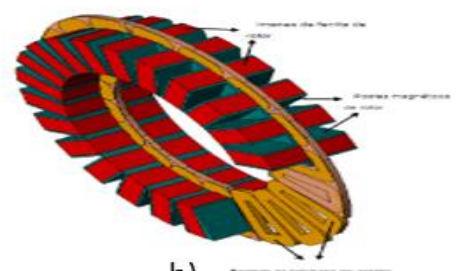

b)

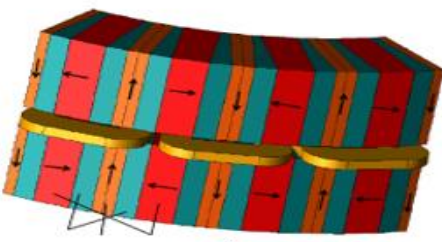

c)

Figure 6: Double Rotor Variants: a) Built-in Radio Type, b) Built-in Radio Hollow type, c) Quasi-Halbach Arrangement [6], [20].

\subsubsection{Two Stators and Single Rotor (AFIR)}

This topology is also called axial flux internal rotor (AFIR) permanent magnet generator [8]. Its main characteristic is the permanent magnets on bothsides of the rotor, which creates a balance between the forces of the stator and the rotor [13]. Further more, the windings of both stators must have the same number of coils and turns [10], and their electrical connection can be in parallel to obtain a higher current or in series if a higher voltage isrequired [13].

\subsection{Multidisc Generator (Multi-Stator, Multi-Rotor)}

In this case, two or more stator and rotor discs mechanically coupled on the same axis $[2,8,14]$ are included, as shown in figure 7 .

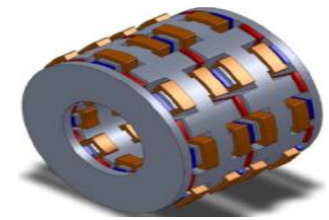

Figure 7: Conventional Multi-Stator Multi-Rotor Model [21]. 
Its main characteristicis the possibility of cascading multiple stages using double rotor or double stator configurations [21], therefore, itis possible to connect or disconnect modules depending on the time requirements that mayexist [3]. However, the magnetic attraction forces due to the multiple air gaps between stator and rotor can cause problems in construction [7].

\subsection{Stator Configuration}

In the above-described topologies, the stator can be of the slottedcore, slotlesscore or coreless type (figure 8).

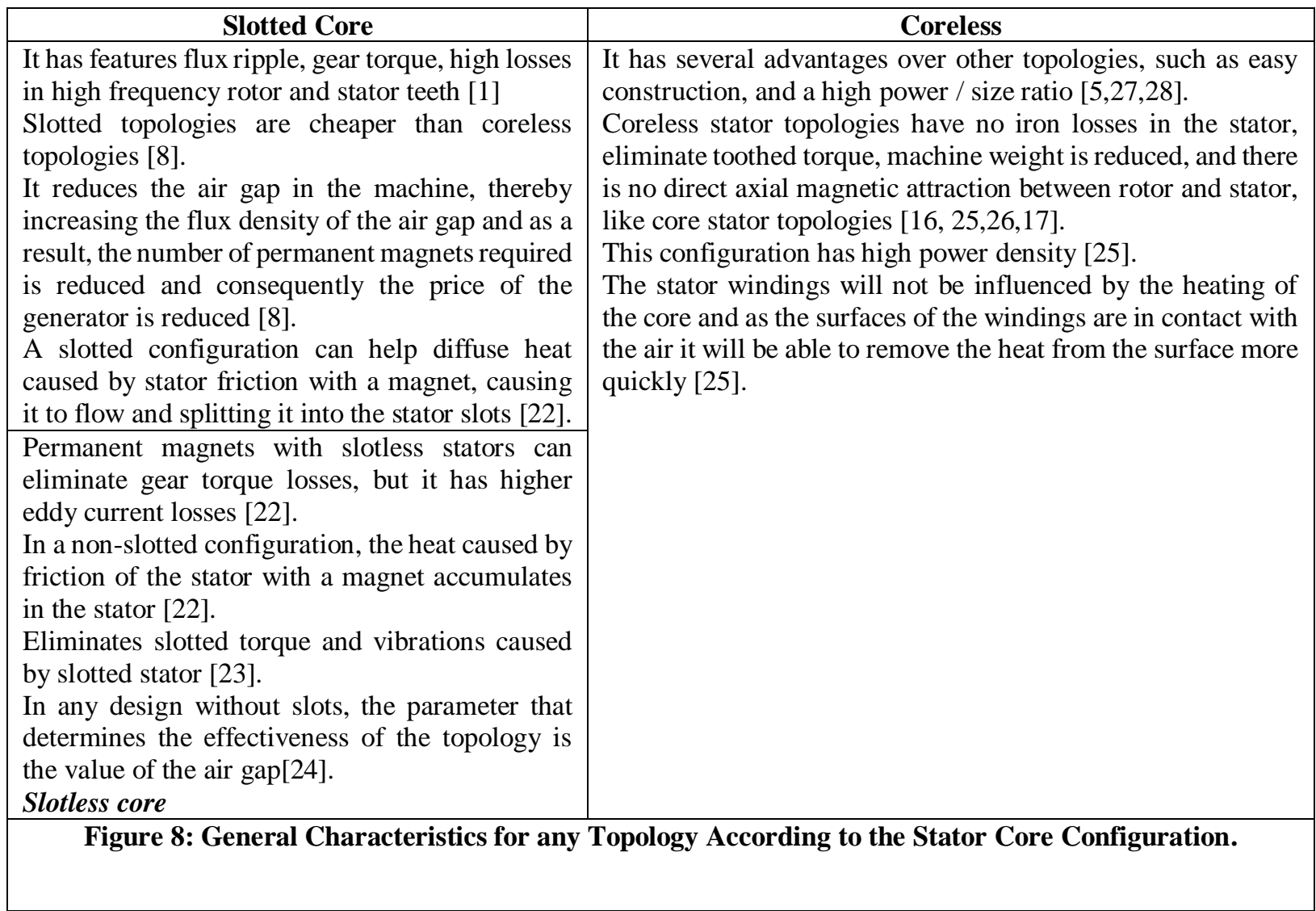

\section{DESIGN OF THE PROPOSED TOPOLOGY}

Taking the information in the previous section as a reference, the double rotor topologyischosen due to its characteristics for low speed and low power applications. Therefore, in this document a variant of this to pology is proposed. The proposed to pologyis a purelycore less configuration, thatis, a coreless stator, with trapezoidal coils, and an ironless rotor with permanent magnets in Halbach arrangement, this new topology is chosen based on the following aspects:

- In double rotor, due to the proposed arrangement of magnets itis possible to eliminate the ironfrom the rotor and use an air-corewinding, in order to reduce the total weight of the generator.

- For the Halbach type arrangement of the permanent magnets, neodymium magnets are chosen, to allow good ventilation to the new topologywith axial magnetization.

- A coreless stator, as it eliminates core losses, toothed torque and gear torque, in addition, the gener at or becomes lighter.

- Greaterefficiency in low power wind turbine applications, by eliminating iron losses, gear torque, and having a 
lowstarting torque.

- $\quad$ Easy fabrication and construction of the topology

- The coils are trapezoidal in shape, to achieve a greater flux, since, by using an air winding, the coilcovers the entire pole area, and therefore the winding will belarge rthan the external diameter of the rotor.

- Concentrated windingis used, as it requires less copper, and improves efficiency by minimizing copper losses.

- As the topology is fully coreless, the outer and inner diameter will be the outer and inner dimensions of the magnet, so the magnet will have a similar trapezoidal shape.

For the design of this topology, the main parameters for sizing are the number of revolutions, output power, number of poles, number of coils, number of turns per coil, outer and inner diameter of the rotor, determination of the magnetic flux, output voltage, and the symmetric distribution of magnets and coils [24, 29]. Another important criterion to take into account in the design is the relationship between poles and coils for theirproperchoice [26], and the value of the air gap, especially in the case of a stator without slots, since this parameter determines the effectiveness of the generator [24].

In $[26,29]$ it is proposed that an adequate number of poles is required for correct operation at low wind speeds, in addition, itis possible that both the core and the stator windings are heated, therefore, a way to improve the cooling, is to adjust the air gap distance, the shape of the core [4], or the appropriate combination of poles and grooves [30].

Taking the described parameters as references, the criteria of the machine are a maximum output power of 10 watts, a wind speed of $1.8 \mathrm{~m} / \mathrm{s}$ and a maximum rotor outer diameter of $300 \mathrm{~mm}$. With the value of the outer diameter, the inner diameter is determined (1), with the ratio factor $(\lambda)$ proposed by [13] :

$$
\lambda=\frac{D_{\text {inner }}}{D_{\text {outer }}} \simeq \frac{1}{\sqrt{3}}
$$

A number of poles is chosen for the design of the machine, which must be an even number, and with this the number of coils $\left(N_{c}\right)$ for the stator is determined $[21,27,29]$ :

$$
N_{c}=\frac{3}{4}(\# \text { poles })
$$

With equation (2) the number of coils per phase, $N_{c p}$, is determined and $\mathrm{m}=3$ is taken, since the proposed topologyis three-phase (3).

$$
N_{c p}=\frac{N_{c}}{m}
$$

With the number of poles, the polar step is als ocalculated with (4)

$$
P p=\frac{360^{\circ}}{\# p o l e s}
$$

Since the rotor has an outside diameter and an insidediameter, the pole pitch is calculated with equation (5), for both the inside and outside diameter.

$$
P_{\text {protor }}=P_{p} * \frac{\pi}{180^{\circ}} * \frac{D_{\text {rotor }}}{2}
$$

Taking into account the synchronous speed $\left(N_{S}\right.$, obtained from the wind speed), the outer diameter of the rotor and the number of pairs of poles, the working frequency $(f)$ for the generatorisdetermined [10, 12, 13, twenty-one]. 


$$
f=\frac{N_{S}^{*} \# \text { poles }}{120}
$$

To determine the number of turns per coil, the equation (7) [17] isused :

$$
N=\frac{E_{f}}{4,44 * f * k_{w^{*}} \emptyset_{m a ́} x}
$$

The winding factor $k_{w}$ isequal to 1 , due to the type of winding and stator used for the proposedtopology. It isknownthat the maximum flux $\emptyset_{m a ́ x}$ at the magneticpolesis, the productbetween the magnetic flux density and the area:

$$
\emptyset_{m a ́ x}=B_{m g} * A_{m}
$$

At the designer's discretion, the air gap distance ischosen in such a way that an induction value is obtained in the eastof $B_{m g}=0,8 \mathrm{~T}, \mathrm{t}$, taking into accountthat a Halbach matrix will beused for magnetization. With this value, the expected induced voltage $\left(E_{f}\right)$, and replacing equation (8) in (7), the number of turns in the coilis calculated with equation (9).

$$
N=\frac{E_{f}}{4,44 * f *(0,8) * A_{m}}
$$

\section{RESULTS}

For the purely coreles stopology, an outer rotor diameter of $250 \mathrm{~mm}$ ischosen, taking into account the final accommodation of the concentrated trapezoida lwinding, in addition, taken to the long ends, a large number of poles are required, for which 12 poles are chosen, and the expected induced voltage for thist opologyis 10 volts. Table 2 shows the dimensions obtained for this configuration using formulas (1) - (9):

Table 2: Purely Coreless Topology Dimensions.

\begin{tabular}{|l|l|l|}
\hline \multicolumn{1}{|c|}{ Parameter } & & Dimenssions \\
\hline External diameter & $\mathrm{D}_{\text {outer }}$ & $250 \mathrm{~mm}$ \\
Inside diameter & $\mathrm{D}_{\text {inner }}$ & $140 \mathrm{~mm}$ \\
Number or poles & $\#$ poles & 12 \\
Number of coils & $\mathrm{N}_{\mathrm{c}}$ & 9 \\
Coils per phase & $\mathrm{N}_{\mathrm{cp}}$ & 3 \\
Air gap & $\mathrm{g}$ & $3 \mathrm{~mm}$ \\
Outer pole passage & $\mathrm{Pp}_{\text {outer }}$ & $65,45 \mathrm{~mm}$ \\
Inner pole passage Synchronous & $\mathrm{Pp}_{\text {intinner }}$ & $36,65 \mathrm{~mm}$ \\
speed & $\mathrm{N}_{\mathrm{s}}$ & $137,51 \mathrm{rpm}$ \\
Frequency & $\mathrm{f}$ & $13,75 \mathrm{~Hz}$ \\
Number of turns & $\mathrm{N}$ & 270 \\
IP large & $\mathrm{IP}_{\text {large }}$ & $55 \mathrm{~mm}$ \\
IP outdoor wide exterior & $\mathrm{IP}_{\text {outwide }}$ & $16,36 \mathrm{~mm}$ \\
IP high & $\mathrm{IP}_{\text {high }}$ & $7 \mathrm{~mm}$ \\
IP indoor wide & $\mathrm{IP}_{\text {indwide }}$ & $9,16 \mathrm{~mm}$ \\
High stator & $7 \mathrm{~mm}$ \\
\hline
\end{tabular}

Using the Autocadtool, the location of the magneticpoles and the coilsis carried out, taking into accountthat for a Halbach matrix, 4 magnets form a magnetic pole, figure 9a. shows the location of the coil with respect to the magnetic pole, in which, the long end of the winding, and the covered pole area are observed. The resulting configuration for 12 poles and 9 coils ( 3 per phase) isshown in figure $9 \mathrm{~b}$ : 

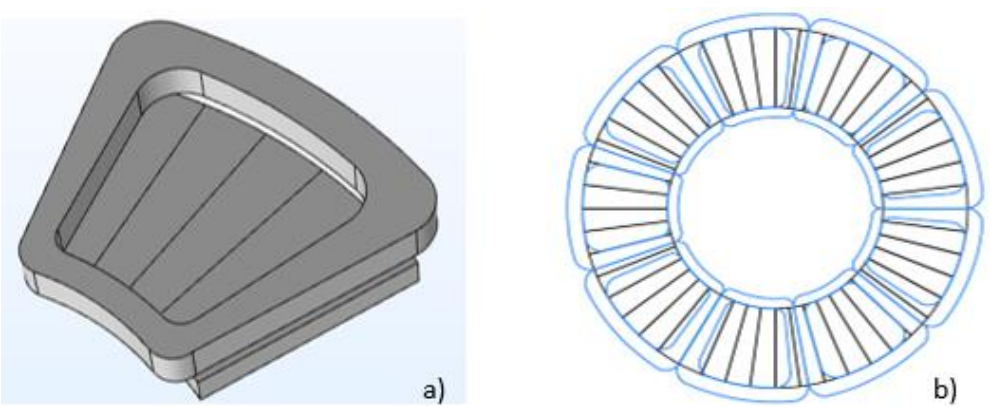

Figure 9: a) Location of the Trapezoidal Winding and Permanent Magnets. b) Magnet and Coil Arrangement Topology.

After carrying out the theoretical calculations for the proposed topology, the configuration is simulated in the COMSOL software, to validate the information through the finite element method.

The results obtained for the magnetic flux density are shown in figure 10, where itis observed that by implementing a Halbach matrix for the permanent magnets and thus avoiding the rotor iron, itdoes not present a large dispersion flux, which increases density in the air gap and thus improves efficiency.

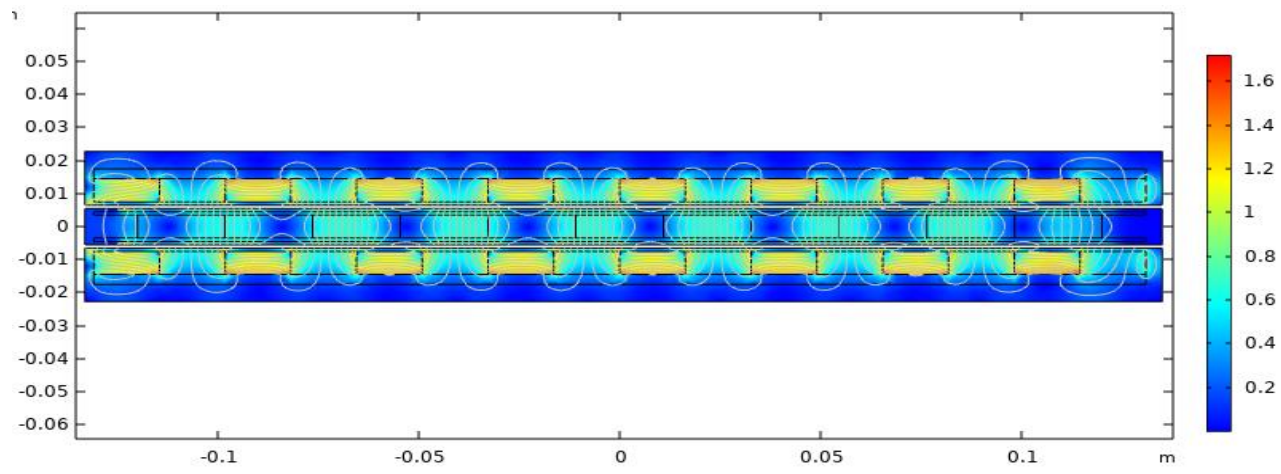

Figure 10: Magnetic Flux Density Topology.

The output voltages obtained for the topology without load and underload are shown in figures 11 and 12 , the voltage value in the winding obtained in emptyis close to that calculated in the design with a value of 13 volts in two of the phases, however, in one of the phases thereis a distortion in the wave, with a voltage of approximately 10 volts. For the voltage withload, a decrease in value isobserved at an output voltage of 6 volts, the same wave form is maintained for all three phases. There are errors in the phase shift for the angles of the wrapping tension due to the low power required for the design and the proposed distribution for the winding.

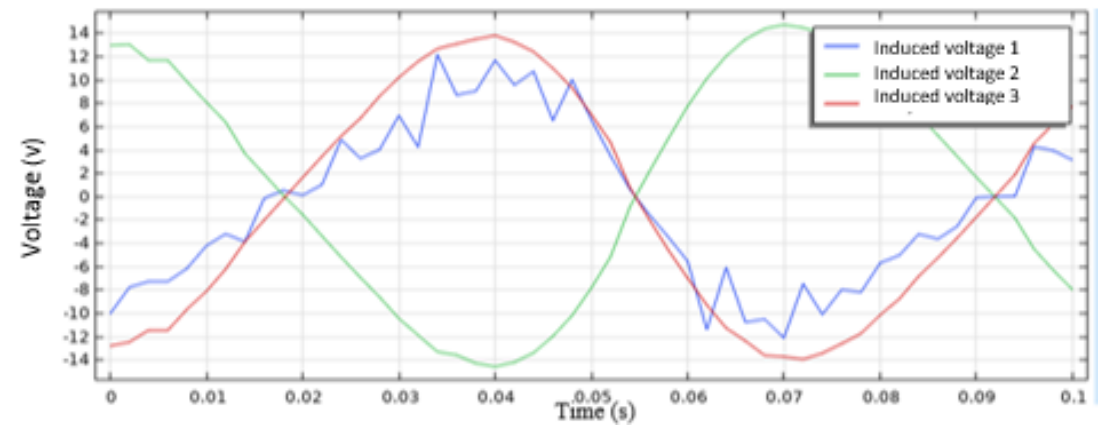

Figure 11: Voltage of Winding Topology Without Load. 


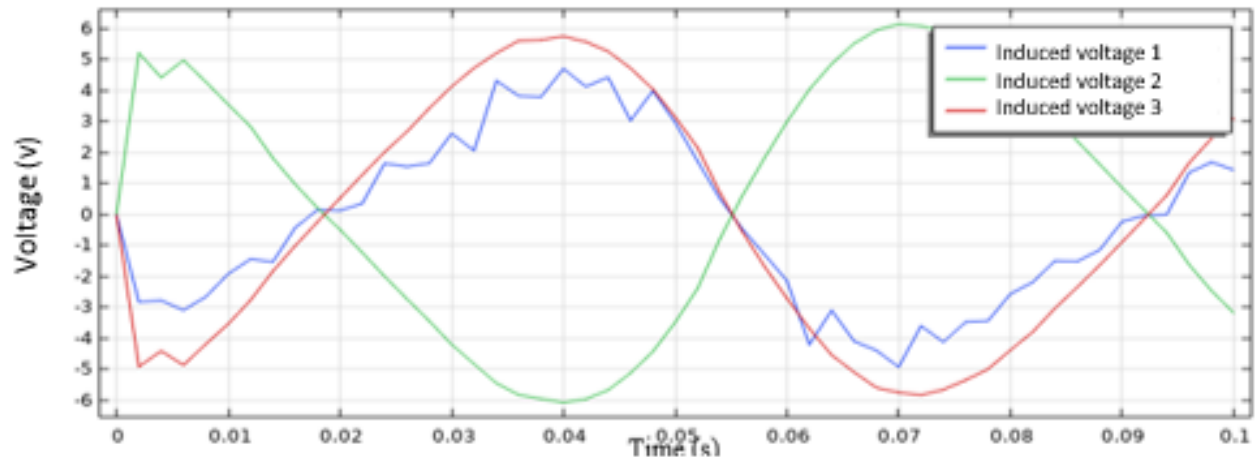

Figure 12: Voltage of Winding Topology with Load.

The output power underload, for the topology, is kept within the established design parameters with a maximum value of 3 watts (figure 13).

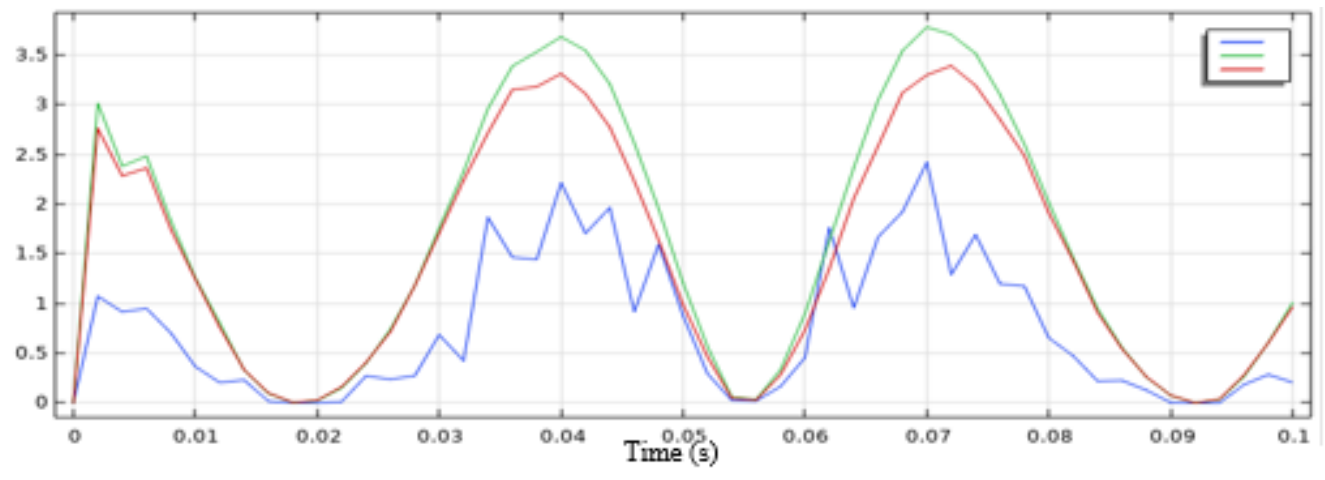

Figure 13: Power Output Topology.

\section{CONCLUSIONS}

This document demonstrated the possibility of implementing a double rotor generatoriron less, therefore, the proposed topology uses the Halbach matrix for the location of the permanent magnets in the rotors. This magnetizationpreventsstray flux fromoccurring due to the absence of iron, and a higher flux concentration isachieved in the air gap, in addition to reducing the overall weight of the generator. In the analysisbased on finiteelements, it shows that the behavior of the proposed topology is close to the results obtained by analytical means, thus demonstrating that the fully coreless topology performs well for low power and low speed applications.

Thanks to the implementation of the finite element method in the modeling of a new axial fluxgenerator, itis possible to face the topology to variouswork scenarios, without the need for a model construction, to analyze the behavior.

\section{REFERENCES}

1. Nataraj\& B. Ramasamy. (2017). Modeling and FEA analysis of axial flux PMG for low speed wind turbine applications. 2017 International Conference on TechnologicalAdvancements in Power and Energy (TAP Energy), 1-5, Kollam.

2. S. S. Laxminarayan, M. Singh, A. H. Saifee\& A. Mital. (2017). Design, Modeling and Simulation of Variable Speed Axial Flux Permanent Magnet Wind Generator. ELSEVIER, Sustainable Energy Technologies and Assessments, India.

3. F. González Velázquez. (2017). Optimización de Banco de Pruebas y Sistema de Monitoreo deAerogenerador de Baja Potencia (Final technologist job). Centro de Ingeniería y DesarrolloIndustrial, Santiago de Querétaro. 
4. G. Ahmad \& U. Amin. (2016). Design, Construction and Study of Small-Scale Vertical Axis Wind Turbine based on a MagneticallyLevitated Axial Flux Permanent Magnet Generator. ELSEVIER, Renewable Energy.

5. M. Castillo García. (2017). DiseñoElectromagnético de un GeneradorEléctrico para Turbina Eólica de 100 kW(Final degreeproject).Universidad Politécnica de Madrid, Madrid, España.

6. M.M. Radulescu, S. Breban\& M. Chirca. (2016). Novel topologies of low-speed axial-flux permanent- magnet microwindgenerator. The 18 th National Conference on Electrical Drives, CNAE 2016, Acta Electrotechnica, 57 (3-4), Special Issue.

7. J. Kappatou, G. Zalokostas\& D. Spytatos. (2017). 3-D FEM Analysis, Prototyping and Tests of an Axial Flux Permanent-Magnet Wind Generator. Energies, Greece.

8. R. D. Chavan\& V. N. Bapat. (2016). The study of different topologies of Axial Flux Permanent Magnet generator. IEEE, 2016 International Conference on Automatic Control and Dynamic Optimization Techniques (ICACDOT), 202-206, Pune.

9. T. Asefi, J. Faiz\& M. A. Khan. (2018). Design of Dual Rotor Axial Flux Permanent Magnet Generatorswith Ferrite and RareEarth Magnets. IEEE, 18th International Power Electronics and Motion Control Conference (PEMC), Budapest.

10. Yicheng Chen, PragasenPillay\& A. Khan. (2004). PM windgeneratorcomparison of different topologies. IEEE,Conference Record of the 2004 IEEE Industry Applications Conference, 39th IAS Annual Meeting, 3, 1405-1412, Seattle, WA, USA.

11. R. Rusmana, A. A. Melkias, N. Nurrohman\& I. M. W. Kastawan. (2019). Voltage GenerationCharacteristics of an Axial Flux Permanent Magnet (AFPM) Generator. IOP ConferenceSeries: Materials Science and Engineering, ICIEVE, Indonesia.

I. M. W. Kastawan\&R.usmana.(2017). Voltage Generation of Three-Phase Double SidedInternal Stator Axial Flux Permanent Magnet (AFPM) Generator, IOP ConferenceSeries: Materials Science and Engineering.Indonesia.

12. S. Khan, S. Amin \& S. S. Hussain Bukhari. (2019). Design and Comparative Performance Analysis of Inner Rotor and Inner Stator Axial Flux Permanent Magnet SynchronousGenerator for Wind Turbine Applications. IEEE, International Conference on Computing-iCoMET, Sukkur IBA University, Pakistan.

13. H. Gor\& E. Kurt. (2015).WaveformCharacteristics and Losses of a New Double Sided Axial and Radial Flux Generator. ELSEVIER, ScienceDirect, Turkey.

14. E. Celik, H. Gör, N. Öztürk\& E. Kurt. (2017). Application of Artificial Neural Network to Estimate Power Generation and Efficiency of a New Axial Flux Permanent Magnet SynchronousGenerator. ELSEVIER, ScienceDirect, Turkey.

15. H. Gör\& E. Kurt. (2016). Preliminary Studies of a New Permanent Magnet Generator (PMG) with the Axial and Radial Flux Morphology. ELSEVIER, ScienceDirect, Turkey.

16. N. Anitha\& R. Bharanikumar. (2019). Design and Analysis of Axial Flux Permanent Magnet Machine for Wind Power Applications. IEEE, International Conference on Power Electronics Applications and Technology in Present Energy Scenario (PETPES), India.

17. J. Chalmers\& E. Spooner. (1999). An axial-flux permanent-magnet generator for a gearlesswindenergy system. IEEE Transactions on Energy Conversion, 14 (2), 251-257.

18. R. Mirzahosseini, A. Darabi\& M. (2020). Assilli. Analytical and ExperimentalAnalysis of Back EMF Waveform of a TORUSType Non-Slotted Axial Flux Permanent Magnet Synchronous Machine withShifted Rotor. ELSEVIER, Measurement, Iran.

19. M. Chirca, S. Breban, C. Oprea\& M. M. Radulescu. (2015). Comparative design analysis of ferrite-permanent-magnet microwind turbine generators. IEEE, ACEMP,OPTIM\&ELECTROMOTION, 687-692, Side.

20. Habib, H. Che, N. Rahim, M. Tousizadeh\& E. Sulaiman. (2020). A fullycoreless Multi-Stator Multi-Rotor (MSMR) AFPM 
generatorwith combination of conventional and Halbach magnet arrays. Alexandria Engineering Journal, 59, Issue 2, 589-600.

21. M. Irfan, R. F. Ariyanto, L. Syafaah, A. Faruq\& N. Subeki. (2020). Stator Slotted Design of Axial Flux Permanent Magnet Generator for Low-Speed Turbine. IOP ConferenceSeries: Materials Science and Engineering, ICEAT, Indonesia.

22. H. Polinder. (2013). 2 - Principles of electrical design of permanent magnet generators for direct drive renewableenergysystems. WoodheadPublishing Limited, Delft University of Technology, 30-50, The Netherlands.

23. V. N. Antipov, A. D. Grozov\& A. V. Ivanova. (2019). Design and Analysis of a New Axial Flux Permanent MagnetSynchronousGenerator for Wind. IOP ConferenceSeries: Materials Science and Engineering, International Scientific Electric Power Conference.

24. M. R. Minaz\& M. Celebi. (2016). Design and Analysis of a New Axial Flux Coreless PMSG withThree Rotors and Double Stators. Elsevier, Results in Physics, Turkey, 2016.

25. M. Dranca, M. Chirca\& S. Breban. (2019). Comparative Design Analysis of Axial Flux Permanent Magnet Direct-Drive Wind Generators. IEEE, The 11st International Symposium on Advanced Topics in Electrical Engineering, Romania.

26. N. E. Lastra. (2019). Diseño y Construcción de un Generador de Flujo Axial con Imanes Permanentes de BajoCosto para AplicacionesEólicas.ResearchGate.

A. Rasekh, P. Sergeant\& L. Vierendeels. (2016). FullyPredictiveHeat Transfer Coefficient Modeling of an Axial Flux Permanent Magnet Synchronous Machine withGeometricalParameters of the Magnets. ELSEVIER, Applied Thermal Engineering.

27. M. Carrillo, C. Claudio \& A. Mayorga. (2018). Caracterización de un generador de flujo axial para aplicaciones en energíaeólica. Science and Technology Magazine, INGENIUS, 19, 19-28.

28. S. J. Arand\& M. Ardebili. (2016). Cogging Torque Reduction in Axial-Flux Permanent Magnet Wind GeneratorswithYokeless and Segmented Armature by RadiallySegmented and PeripherallyShifted Magnet Pieces. ELSEVIER, Renewable Energy, Iran. 
